\title{
Climate change and asset prices: are corporate carbon disclosure and performance priced appropriately?
}

Article

Accepted Version

Liesen, A., Figge, F., Hoepner, A. G. and Patten, D. M. (2017) Climate change and asset prices: are corporate carbon disclosure and performance priced appropriately? Journal of Business Finance \& Accounting, 44 (1-2). pp. 35-62. ISSN 1468-5957 doi: https://doi.org/10.1111/jbfa.12217 Available at https://centaur.reading.ac.uk/67088/

It is advisable to refer to the publisher's version if you intend to cite from the work. See Guidance on citing.

To link to this article DOI: http://dx.doi.org/10.1111/jbfa.12217

Publisher: Wiley

All outputs in CentAUR are protected by Intellectual Property Rights law, including copyright law. Copyright and IPR is retained by the creators or other copyright holders. Terms and conditions for use of this material are defined in the End User Agreement.

www.reading.ac.uk/centaur 
Central Archive at the University of Reading

Reading's research outputs online 


\title{
Climate Change and Asset Prices:
}

\section{Are Corporate Carbon Disclosure and Performance Priced Appropriately?}

\begin{abstract}
:
This paper empirically assesses the value relevance of information on corporate climate change disclosure and performance to asset prices, and discusses whether this information is priced appropriately. Findings indicate that corporate disclosures of quantitative GHG emissions and, to a lesser extent, carbon performance are value relevant. We use handcollected information on quantitative greenhouse gas (GHG) emissions for 433 European companies and build portfolios based on GHG disclosure and performance. We regress portfolios on Carhart (1997) four factor models extended for industry effects over the years 2005 to 2009. Results show that investors achieved abnormal risk-adjusted returns of up to $13.05 \%$ annually by exploiting inefficiently priced positive effects of (complete) GHG emissions disclosure and good corporate climate change performance in terms of GHG efficiency. Results imply that, firstly, information costs involved in carbon disclosure and management do not present a burden on corporate financial resources. Secondly, investors should not neglect carbon disclosure and performance when making investment decisions. Thirdly, during the period analysed financial markets were inefficient in pricing publicly available information on carbon disclosure and performance. Mandatory and standardised information on carbon performance would consequently not only increase market efficiency but result in better allocation of capital within the real economy.
\end{abstract}

Keywords: carbon disclosure, climate change, value relevance, disclosure quality, GHG emissions, market efficiency, stock performance 


\section{Climate Change and Asset Prices:}

\section{Are Carbon Disclosure and Emission Performance Priced Appropriately?}

\section{Introduction}

Climate change has developed into a widely accepted threat to our planet that requires urgent regulatory responses (Stern 2006; IPCC 2007). Within the European Union (EU), the European Union Emissions Trading Scheme (EU ETS), the EU policy guiding principles to make polluters pay (European Council 2006) and national taxes on energy use and carbon dioxide are just a few examples of political initiatives aiming to reduce climate change. At the same time, market initiatives such as the Carbon Disclosure Project (CDP) (Carbon Disclosure Project 2008) and the Climate Principles (The Climate Group 2012) have been established to motivate reductions in corporate GHG emissions, turn "climate change into a business risk" (Pattberg 2012, p. 619), or to allow investors to better grasp the financial risk stemming from climate change.

Among companies, the concern that climate change impacts or potentially impacts financial performance appears to be widely recognised: Out of the 358 FT500 companies that responded to the CDP during the earlier years covered in this study, $87 \%$ reported that climate change constitutes a commercial risk and/or challenge to their business (Carbon Disclosure Project 2006). On financial markets, as a consequence of these risks and the imminent challenge to transform to a low carbon economy, a significant re-distribution of shareholder wealth is expected to take place (Carbon Trust 2006). Nevertheless, and despite the growth of the socially responsible investment (SRI) industry in recent decades, market participants only slowly adjust their investment behaviour to incorporate the financial risks resulting from political and market initiatives for the mitigation of climate change. For example, it was estimated that during one of the years investigated in this study less than $0.1 \%$ of the over $\$ 40$ 
trillion in assets of the investors that are signatories to the CDP were "invested in any investment strategy which explicitly and systematically takes climate risk into account" (Innovest 2007, p. 3).

Investment practitioners generally expect that financial markets are "only beginning to recognise the magnitude of impact the transition to a low carbon global economy will have on companies' competitive positions and long-term valuations" (The Goldman Sachs Group 2009, p. 2), and as a result the financial risk represented by political and market initiatives for the shift towards a low-carbon economy "may not yet be fully reflected in share prices" (FTSE Group 2012, p. 4). ${ }^{1}$ These statements from the investment practitioner community suggest a potential inefficiency of the market to appropriately price information on the financial risk stemming from climate change. According to the efficient markets hypothesis (EMH), efficient financial markets price available information (Fama 1970). Moderate proponents of EMH argue that markets in practice are fairly - but not always - efficient (Worthington et al. 2004; Renshaw 1984). When markets are inefficient, market participants can use value relevant information, i.e. information that is relevant to the future earnings potential of a stock, to achieve abnormal risk-adjusted returns. Once identified, market participants will erase these abnormal risk-adjusted returns by trading on the underlying information and, as a result, turn financial markets efficient (Lee 2001). Stock markets are thus made efficient by market participants believing they are inefficient (Dimson et al. 1998; Grossmann et al. 1980), searching for inefficiencies and acting on arbitrage opportunities. The same underlying process is valid for the appropriate pricing of value relevant information on corporate sustainability performance. As noted by, for example, Derwall et al. (2005) and Renneboog et al. (2008), risk-adjusted returns of companies with good sustainability performance will only be persistently higher than those of companies with poor sustainability

\footnotetext{
1 Similar conclusions can also be drawn for the granting of corporate bank loans (Hoepner et al. 2016).
} 
performance when the financial market does not price information on sustainability performance efficiently.

In the context of this study, the market inefficiency to price the financial risk stemming from climate change appropriately hinted at by investment practitioners above allows us to determine whether information on corporate carbon disclosure and performance is value relevant. To empirically assess this research question, a Carhart four factor model (C4FM) (Carhart 1997) extended for industry effects is applied to a sample of 433 European companies over the years 2005 to 2009 , inclusive. We build portfolios using a unique data set of hand-collected information on quantitative corporate GHG emissions disclosure practices and performance gathered from corporate reports. Results suggest that quantitative corporate carbon disclosure and, to a lesser extent, carbon performance were relevant to asset prices of European companies and not priced appropriately during our period of investigation. Investors could achieve abnormal risk-adjusted returns of up to $13.05 \%(\mathrm{p}<0.01)$ per year when investing in portfolios constructed from (complete) GHG emissions disclosure and, to a lesser extent, good corporate climate change performance expressed as GHG efficiency. We find only very limited support for information on absolute levels of GHG emissions being relevant to asset prices. Results are robust to various further tests controlling for, among other things, national differences in environmental fiscal policies, other non-financial disclosure by corporations, the completeness of corporate GHG emissions disclosure, the impact of the financial crisis and the EU ETS.

Our results have implications for investors, companies and regulators. For investors, our findings suggest that information on corporate carbon disclosure and performance must be taken into account in investment analysis, as they are relevant for financial markets. For companies, results show that the information costs for (complete) corporate carbon disclosure and efficiency management do not present a burden on corporate financial resources. To the 
contrary, our findings suggest that for example companies not disclosing (complete) information on quantitative GHG emissions are valued less by financial markets, thus generating a strong argument for companies to engage in high-quality non-financial disclosure in order to reduce information asymmetry. For the real economy, the inefficient pricing of publicly available information on carbon disclosure and performance results in an inefficient allocation of capital, given that investments in real assets are heavily influenced by the valuation of financial assets. This could impede economic growth (Hayek 1941) and creates a strong argument for regulators to enforce mandatory and standardised information on carbon performance, which would not only increase market efficiency but result in a better allocation of capital within the real economy.

The remainder of this paper is organised as follows. Section 2 provides an analysis of existing related literature. Section 3 develops our hypotheses. Section 4 describes the research methodology, sample and data. Section 5 presents our empirical results, and Section 6 provides a discussion of the implications of our findings.

\section{Prior Studies}

Interest in whether financial markets value corporate sustainability disclosure and performance (CSP) dates back to at least the 1970s, but studies controlling for factors nowadays known to influence stock market performance (use of a C4FM) are relatively limited. Controlling for such factors is however particularly important in the context of SRI, as SRI portfolios have been found to rely quite heavily on small stock and stock with a low book to market ratio (Cortez et al. 2012). Using the C4FM, and thus controlling for systematic risk (Sharpe 1964; Lintner 1965; Mossin 1966), company size (Banz 1981), book to market ratio (Fama et al. 1992) and the momentum effect (Jegadeesh et al. 1993), ensures that abnormal returns found can be attributed to the impact of CSP. At the same time, industry 
composition is generally thought to impact portfolio returns and Dess et al. (1990) argue that not controlling for industry effects can result in a misleading interpretation of results.

Within the domain of studies using the C4FM, Kempf and Osthoff (2007) rely on the socially responsible ratings from KLD Research \& Analytics and find that following the simple trading strategy of buying stocks with high ratings and selling stocks with low ratings over the 1992-2004 time frame, using industry-balanced investment portfolios, resulted in significant annualised alphas of up to $8.7 \%$. Similarly, but focusing more specifically on environmental performance, Derwall et al. (2005) used eco-efficiency scores from the rating agency Innovest Strategic Value Advisors and examined returns for a sample ranging from 170 to 450 U.S. companies over the 1995 to 2003 time period. Also constructing portfolios according to simple trading rules, Derwall et al. document that, controlling for industry effects, firms performing "relatively well along environmental dimensions collectively provide superior returns" (Derwall et al. 2005, p. 58). More specifically, they found an annualised alpha of around $6 \%$ for a strategy that goes long in the best-in-class environmental portfolio and short in the worst-in-class environmental portfolio.

Finally, and most closely related to our investigation, Ziegler et al. (2011) looked at between 447 and 1790 European and U.S. firms over the years 2001 to 2006, inclusive. They built portfolios based on two binary dummy indicators for corporate climate change disclosure derived from the Asset 4 data base. The indicators represent information on whether a company reports if "it believes that climate change can represent commercial risks and/or opportunities" (Ziegler et al. 2011, p. 1287) or not and if a company reports "on initiatives or new production techniques, to recycle, reduce, reuse, substitute or phase out $\mathrm{CO}_{2}$ or $\mathrm{CO}_{2}$ equivalents in the production process" or not (Ziegler et al. 2011, p. 1287). Applying a C4FM, they fail to find significant out- or underperformance of any portfolio over the whole period under investigation. However, in additional tests they show risk-adjusted abnormal returns for 
the energy sector in the U.S. and for the sub-period of 2004 to 2006 in Europe. These results thus highlight that value relevance of information can differ between industries and across time periods.

Each of the recent studies summarized above suggests that CSP information may be relevant to financial markets and inappropriately priced. We extend this body of research by examining the value relevance and pricing of quantitative carbon disclosure and performance in a large European sample over a period of five years, controlling for factors known to explain stock performance and industry effects.

\section{Hypothesis Development}

Political and market initiatives for the reduction of global warming inflict unknown future costs on companies and thus are an important factor in making corporate carbon disclosure and performance relevant to asset pricing. In the European Union, the EU ETS is currently the cornerstone of policies combating climate change, but in addition to the EU ETS various other political and market initiatives target the reduction of GHG emissions. For example, various European countries have introduced some form of tax on carbon dioxide. The likelihood of remaining European countries to tax carbon remains to some extent unpredictable. The abrupt cancellation on the introduction of a significant carbon tax in France one month prior to its introduction is a case in point (Kanter 2009). Political uncertainties also continue to exist at the level of European policy, where the guiding principles of the renewed EU Sustainable Development Strategy include making polluters pay and integrating climate change in all relevant European policies (European Council 2006). However, it continues to be unclear into which specific measures these intended policies and principles for a reduction of GHG emissions will translate. Nevertheless, Sullivan (2009) generally summarizes that policy measures to reduce GHG emissions will grow and not only affect heavy emitters but all companies. 
The uncertainty from the political environment underlies several market initiatives that relate to the financial risk stemming from climate change. Examples include the CDP (Carbon Disclosure Project 2008), the Climate Principles (The Climate Group 2012), the Investor Network on Climate Risk (Investor Network on Climate Risk 2010), The Institutional Investors Group on Climate Change (IIGCC 2010) and The Carbon Principles (The Carbon Principles Banks 2008). The politically induced value relevance of corporate carbon disclosure and performance is consequently also reinforced through these market initiatives.

To examine the relevance of corporate carbon disclosure and performance to asset prices we rely on four proxies, each capturing differences in climate change disclosure or performance. We distinguish between disclosure and performance, as they relate to different estimation and information risks and Doda et al. (2015) suggest there is not necessarily a relation between the existence of corporate carbon disclosure and carbon performance.

Our first disclosure proxy is the existence of disclosure of absolute levels of GHG emissions. In addition to the political and market initiatives discussed above, arguments rooted in stakeholder theory (Freeman 1994) and legitimacy theory (Deegan 2007) suggest that information on corporate GHG emissions could be relevant to the valuation of the firm. Corporate climate change disclosure answers the call from various stakeholder groups for information on corporate contributions to global warming (Kolk et al. 2008; Doda et al. 2015). Disclosure may foster stakeholder support and help ensure that corporate actions are seen as legitimate, i.e. "desirable, proper, or appropriate" (Suchman, 1995, p. 574), thus preventing stakeholder actions that could negatively impact the financial performance of the firm. Additional arguments for the value relevance of corporate carbon disclosure relate to estimation and information risk. Generally speaking, stocks for which only limited information is available have higher estimation risk (Barry et al. 1985), as higher levels of value relevant information on a stock allow for a better and more reliable estimation of its 
specific future cash flow. Riedl et al. (2009, p. 25) summarize that when investors cannot obtain sufficient company-specific information they base their valuation on firm-unspecific information. The disclosure of GHG emissions should thus allow for better estimation of specific future cash flows, as market participants do not have to infer their estimates on less specific information on exposure to the financial implications of climate change (Aerst et al. 2008). In this context of estimation risk, for example, Dhaliwal et al. (2012) show that the existence of CSR disclosure reduces the level of analyst forecast error.

At the same time, prior research (Hassel et al. 2006; Campbell et al. 2011; Deegan et al. 1997) documents that stock brokers and mainstream analysts do not incorporate environmental information in the majority of their decision making processes or investment recommendations. These findings, together with the statements of the investment practitioner community summarized above, lead us to believe that financial markets may be inefficient in pricing carbon disclosure and performance appropriately. If so, value relevance would manifest itself as performance differences of risk-adjusted returns between portfolios constructed from companies disclosing and those not disclosing quantitative GHG emissions. We consequently hypothesize:

H1: Portfolios constructed from companies disclosing and those not disclosing quantitative GHG emissions show differences in risk-adjusted returns.

In addition to analysing the relevance of the choice to disclose GHG emissions information, we also examine the relevance of the completeness of corporate disclosure of absolute levels of GHG emissions. Several studies argue that information quality is relevant to asset prices (Leuz et al. 2005; Francis et al. 2005; Kim et al. 2010) while other studies show that the quality of quantitative carbon disclosure is low (Sullivan 2009; Dingwerth et al. 2010; Liesen et al. 2015). Our proxy for information quality is represented by the completeness of corporate disclosure of quantitative GHG emissions, measured by means of a Disclosure Completeness Index. This Disclosure Completeness Index (DCI) is constructed in line with 
the requirements of the dominant reporting guidelines, i.e. the GHG Protocol (WBCSD 2004), the CDP (Carbon Disclosure Project 2011) and the Global Reporting Initiative (GRI) (Global Reporting Initiative 2000-2006). As we discuss in more detail below, we classify completeness of disclosure relative to scope (i.e. including emissions resulting from both internal corporate activities (scope 1) and electricity purchases (scope 2)), type, (i.e. including not only $\mathrm{CO}_{2}$ but also other GHGs), and reporting boundary (i.e. including emissions on group-wide activities) (cf. Liesen et al. 2015). Because complete disclosure of absolute GHG emissions enables investors to reduce the degree of error in estimating future cash flows (cf. Cormier et al. 2007), it should consequently reduce estimation and information risk (Barry et al. 1985). Assuming the market is in a state of inefficiency with regard to the appropriate pricing of financial risk stemming from climate change during the time of our study, the value relevance of the underlying information would manifest itself as performance differences of risk-adjusted returns between portfolios constructed from companies disclosing complete levels of GHG emissions and those who do not. We hypothesize:

H2: Portfolios constructed from companies disclosing complete levels of GHG emissions and those disclosing incompletely show differences in risk-adjusted returns.

Our third proxy relates to climate change performance and represents companies' levels of absolute GHG emissions. We argue that the magnitude of absolute GHG emission determines a company's exposure and the sensitivity of its returns towards the political, market and stakeholder initiatives for the reduction of climate change discussed above, and is therefore a parameter of estimation risk. The large share of companies with comparatively high absolute levels of GHG emissions is more exposed to, for example, the uncertain future financial liabilities under the EU ETS. Prior studies (e.g. Mahapatra 1984; Luo et al. 2009; Salama et al. 2011) document that companies with good environmental and/or social performance show lower systematic risk, thus suggesting performance is value relevant. As 
described in more detail in below, to operationalise our proxy we categorize companies based on their absolute levels of GHG emissions as high, medium and low emitters. In an inefficient market, portfolios constructed from these different levels of absolute levels of GHG emissions would deliver different risk-adjusted returns. We consequently hypothesize:

H3: Portfolios constructed from companies with high, medium and low absolute levels of emissions show differences of risk-adjusted returns.

Finally, we use the level of GHG efficiency, expressed as the net income in Euro per ton of GHG emissions, as a proxy for climate change performance. We argue that levels of GHG efficiency are a parameter of estimation risk as the future financial performance of companies generating comparatively lower levels of net income per ton of GHG emissions would be impacted more heavily by any future regulatory or market initiatives for the reduction of GHG emissions. The future financial performance of companies with higher GHG efficiency, on the other hand, is less sensitive towards external events on climate change. In this context, for example, Clarkson et al. (2004) show that relative environmental performance indicators developed from Toxics Release Inventory emissions data in the US served as a good predictor of future environmental liabilities for companies in the pulp and paper industry. In an inefficient market, portfolios constructed from different levels of GHG efficiency (as described in detail see section 4) would deliver different risk-adjusted returns. We consequently hypothesize:

H4: Portfolios constructed from companies with high, medium and low GHG efficiency show differences in risk-adjusted returns. 


\section{Research Methods}

\section{Sample}

To test these hypotheses we use a sample of European Union FTSE All World-Index (FTSE AWI) constituents excluding the financial service industry ${ }^{2}$ as of January for each the years 2005 to 2009. FTSE AWI covers companies with large or medium-sized market capitalisation. In total, 433 different companies with 1756 firm-year observations constitute our initial sample (sample A). This initial sample is used to test our proxy referring to the existence of disclosure of GHG emissions. Our second sample - sample B - contains only those companies from sample A that report GHG emissions on at least the majority of corporate activities $^{3}$ in the year preceding index inclusion. Sample B consists of 297 different companies with a total of 1028 firm-year observations, and it is used to test the proxies concerning disclosure completeness, absolute levels of GHG emissions and GHG efficiency.

\section{Empirical Model}

We use a European C4FM (Carhart 1997) extended for industry effects. Although the C4FM has become a standard model (Fama et al. 2010), it has not been used frequently with European samples (von Arx et al. 2014). However, Gregory et al. (2013) show the model is applicable for analysis of larger companies outside the US, and Fama et al. (2011, page 4) summarize that a local (European) model can "capture local average returns rather well". Using a C4FM extended for industry effects (cf. Derwall et al. 2005; Geczy et al. 2005; Hoepner et al. 2011) helps to ensure that abnormal risk-adjusted returns identified in this research are not, in fact, driven by factors already known to determine abnormal stock performance or differing industry composition of portfolios. Not controlling for industry effects can result in a

2 The common practise to exclude financial service companies from the sample is applied in this study as their increased leverage and sensitivity to market developments makes financial service firms incomparable with companies from other industries (Foerster et al. 2005; Shleifer et al. 1997; Fama et al. 1992).

3 Climate change disclosures on less than the majority of corporate activities are not considered here as these do not allow drawing credible conclusions on a company's performance. 
misleading interpretation of results (Dess et al. 1990). This is particularly relevant in the context of this study, as industry affiliation has been found to be a determinant of environmental disclosure practises and performance (Prado-Lorenzo et al. 2009; Dawkins et al. 2010; Brammer et al. 2008), which are the basis for our portfolio construction criteria. To control the returns of a portfolio in the C4FM for industry effects, orthogonalised industry performance variables are added to the model (cf. Derwall et al. 2005; Geczy et al. 2005; Hoepner et al. 2011). Several further design choices have to be made when applying a C4FM, and these are detailed in the remainder of this section. For all portfolios, a buy-and-hold strategy and a long-short trading strategy are applied and are regressed on the C4FM extended for industry effects (model (1)), which is defined as:

$$
\begin{aligned}
R_{i t}-R_{f t}= & \alpha_{i}+\beta_{i}\left(R_{m t}-R_{f t}\right)+s_{i} \text { SMB }_{t}+h_{i} \text { HML }_{t}+p_{i} \text { UMD }_{t}+m_{i} \text { Oil \& Gas }_{t}+ \\
& { }_{i} \text { Basic Materials }_{t}+o_{i} \text { Industrials }_{t}+r_{i} \text { Consumer Goods }_{t}+ \\
& u_{i} \text { Health Care }_{t}+v_{i} \text { Consumer Services }_{t}+w_{i} \text { Telecom }_{t}+y_{i} \text { Utilities }_{t}+ \\
& z_{i} \text { Technology }_{t}+\varepsilon_{i t}
\end{aligned}
$$

Where $\mathrm{R}_{\mathrm{it}}$ is the logarithm of the continuously compounded return of portfolio $i$ at month $t, R_{\mathrm{ft}}$ is the logarithm of the continuously compounded risk-free return rate, $\alpha_{\mathrm{i}}$ is the alpha coefficient representing excess return, $\beta_{\mathrm{i}}$ is the beta coefficient representing systematic risk, $\mathrm{R}_{\mathrm{mt}}$ is the logarithm of the continuously compounded return of the market, $\mathrm{SMB}_{\mathrm{t}}$ is the measure for the historic excess returns of small-cap over large-cap stocks, $\mathrm{HML}_{\mathrm{t}}$ is the measure for the historic excess returns of value stocks over growth stocks, $\mathrm{UMD}_{\mathrm{t}}$ is the measure for the historic excess returns of winner-stocks over loser-stock and $\varepsilon_{\mathrm{it}}$ is the error term that captures the return variation that cannot be explained by the model. $h_{i}$ to $z_{i}$ are the coefficients that measure the sensitivity of the portfolio's return to the different factors and orthogonalised industry returns. 
The three months Euro Interbank Offered Rate (Euribor) is used as the risk-free rate of return $\mathrm{R}_{\mathrm{ft}} \cdot{ }^{4}$ The return of the market $\mathrm{R}_{\mathrm{mt}}$ is depicted by the return of all non-financial European constituents of the FTSE AWI, i.e. all companies in sample A. The calculation of $\mathrm{SMB}_{\mathrm{t}}, \mathrm{HML}_{\mathrm{t}}$ and $\mathrm{UMD}_{\mathrm{t}}$ are carried out in line with Fama et al. (1992) and Carhart (1997), respectively. Given that our sample only includes mid-size and large-cap companies included in a major equity index, we do not exposure our anaylsis the common risk of overrepresenting small illiquid stocks by, for example, choosing incorrect breakpoints for the calculation of $\mathrm{SMB}_{\mathrm{t}}, \mathrm{HML}_{\mathrm{t}}$ and $\mathrm{UMD}_{\mathrm{t}}$ factors (cf. Gregory et al., 2013). The discussion of results in the remainder of this chapter focusses on regression results obtained with equalweighted portfolio returns, which have been regressed on equal-weighted market returns and control variables, as well as equal-weighted SMB, HML and UMD factors. ${ }^{5}$ Value-weighted returns obtained using a model with value-weighted factors are shown in the section on further analysis. .

Industry control variables are the orthogonalised return of a portfolio constructed from companies from a respective industry - based on the FTSE Industry Classification Benchmark (FTSE Group, 2010) - at month t, and represent the share of the return of the industry that cannot be explained by market developments and thus constitute purely industry-specific return characteristics.

4 To convert the three months Euribor into the monthly continuously compounded risk free return an investor would receive each per annum stated return is transformed into a 91 days return by multiplying it with $91 / 365.25$. Subsequently, one is added to the result and the sum is taken to the power of 30.4375/91, whereby 30.4375 is one twelfth of 365.25 days, i.e. one month. The continuously compounded monthly risk free return is then obtained by computing the natural logarithm of the result (Hoepner et al. 2014). weighted returns may be driven by micro-caps and model problems relating to micro-caps (Fama 1998). This argument does however not apply in the context of this study, as our sample only includes mid-size and large-cap companies. 


\section{Data Collection \& Portfolio Formation}

We collected data for accounting figures and stock performance from the Thomson Reuters Datastream data base. Data on Euribor-rates was obtained from www.euribor-rates.eu (Triami Media 2011). For tests of robustness, we extracted the implicit tax rate on energy of each represented country from the publications of the European Commission (Eurostat 2011b), social and governance disclosure rating scores from Bloomberg (Bloomberg 2015) and information on which companies owned installations that were part of the EU ETS from the publicly available data base of Carbon Market Data (Carbon Market Data 2011).

The data collection process for proxies related to climate change disclosure and performance can be summarised as a three step process. First, we collected over 4,000 corporate reports issued by the sample firms over our period of interest. These reports included sustainability reports, CSR reports, environmental reports and financial reports. Second, we hand-reviewed the reports as well as the sample companies' websites and, if no information on GHG emissions were found, answers to the CDP (Carbon Disclosure Project 2011). We extracted GHG emissions data from these sources when they covered at least the majority of corporate activities. In terms of data sources, GHG emissions data were extracted from corporate reports for $84 \%$ of companies in the sample, with approximately one in five data points stemming from annual financial reports and the remaining data points extracted from sustainability reports, CSR reports, environmental reports or companies' websites. For $16 \%$ of companies, emissions data was extracted from the CDP in at least one year. It should be noted that while several European countries introduced guidelines or some form of legislation for environmental, sustainability or CSR reporting before or during the time of this study, a comprehensive and standardized disclosure of absolute numbers of quantitative GHG emissions in Europe was only mandatory for companies that have installations in the EU ETS during the period covered by our investigation. We control for the impact of EU ETS on our results in a test of robustness. 
Finally, we classified the GHG emissions data gathered according to its completeness in line with the requirements of the three dominant voluntary reporting guidelines for corporate GHG emissions, namely the GHG Protocol (WBCSD 2004), the CDP (Carbon Disclosure Project 2011) and the GRI (GRI) (Global Reporting Initiative 2000-2006) (cf. Liesen et al. 2015). More specifically, we classified completeness of GHG emissions reporting in each firm year with respect to:

(i) scope, i.e. including emissions resulting from both internal corporate activities (scope 1) and electricity purchases (scope 2),

(ii) type, i.e. including not only $\mathrm{CO}_{2}$ but also other $\mathrm{GHGs}$, and

(iii) reporting boundary, i.e. including emissions on group-wide activities ${ }^{6}$ Using these classifications, we scored companies' disclosure completeness as follows: a company reporting scope 1 and scope 2 emissions received one point (and zero otherwise). Furthermore, a company reporting on $\mathrm{GHG}$ emissions other than just $\mathrm{CO}_{2}$ received one point (and zero otherwise). Finally, a company disclosing emission on group-wide activities received one point (and zero otherwise). As such, disclosure completeness scores could range from zero to three. While the wording used by companies to describe the scope and reporting boundary of their carbon performance is not standardized, this classification allows for a systematic classification of the completeness of quantitative carbon disclosure. For example, in 2005 Reed Elsevier reported scope $1 \mathrm{CO}_{2}$-emissions (Reed Elsevier 2005, p. 46) for "more than $75 \%$ of our key facilities which account for more than $75 \%$ of our turnover" (Reed Elsevier 2005, p. 43), thus scoring 0 on the DCI, as the company does not report scope 2 emissions, no GHG emissions other than $\mathrm{CO}_{2}$ and no emissions for group-wide activities.

GRI, CDP and the GHG Protocol differ in their requirements for reporting boundaries. CDP and GHG Protocol both demand disclosure of all corporate activities. GRI 3.1 reporting guidelines require that disclosure covers at least all entities that "generate significant sustainability impacts" (Global Reporting Initiative 2011, p. 18). To account for this difference in requirements in our study group-wide activities refers to emissions data covering all or almost all corporate activities; or expressed as a percentage figure more than $90 \%$ of manufacturing activities and more than $90 \%$ of all other activities. 
Diageo, in their 2008 report, show scope 1 and scope 2 GHG emissions (Diageo 2008, p. 22), stating that "environmental data cover production and distribution sites and large office locations (those at which at least 50 employees are based)" (Diageo 2008, p. 36), thus scoring 3 on the DCI. Descriptive statistics for the portfolios constructed from companies' scores on the DCI are displayed in Table 1.

Table 1 around here

Based on the data gathered, we formed portfolios as of January each year, which we updated annually ${ }^{7}$. Focusing on our first disclosure proxy, we formed two mutually exclusive portfolios ('Reporting GHG' and 'Not Reporting GHG') based on a company's choice to disclose GHG emissions data. Next, we constructed portfolios based on the completeness scores. Separate portfolios were constructed for company-years where disclosure scores were zero, one, two, and three, respectively. For example, the '3 DCI Score' portfolio contains only companies reporting complete GHG emissions, i.e. report scope 1 and scope 2 GHG emissions for a group-wide reporting boundary. Turning to our performance proxies, we identified the level of absolute GHG emissions as reported by companies using the disclosures as discussed above. Based on the amount of emissions reported, we classified the sample companies across three categories following the approach of Fama et al. (1995) in their categorisation of companies' market capitalisation for the investigation of the size risk premium: Firms with the highest $30 \%$ of emissions in the sample are classified as high emitters, whereas companies with the lowest $30 \%$ of absolute levels of emissions are considered as low emitters. The remaining $40 \%$ of sample companies are classified as

In a test of robustness reported in Table 3, we construct factors and portfolios in June of each year. The statistical significance of results remains the same. 
medium emitters. We construct separate portfolios across the three classifications ('High GHG', 'Medium GHG' and 'Low GHG').

Finally, to operationalize our GHG efficiency proxy, and similar to the process for GHG emissions, we allocate companies across three separate categories. The $30 \%$ of companies with the highest GHG efficiency scores (calculated as net income in Euros divided by tons of GHG emissions) are placed in the 'High GHG Efficiency' portfolio, the 30\% with the lowest GHG efficiency are included in the 'Low GHG Efficiency' portfolio, and the remaining 40\% of companies are grouped in the 'Medium GHG Efficiency'. Descriptive statistics for the respective portfolios are displayed in Table 1.

\section{Results}

Table 2 presents the results of portfolios regressed on the C4FM extended for industry effects. The Reporting GHG portfolio generates an annualised alpha of $1.72 \%(\mathrm{p}<0.01$, adjusted R-squared of over 99\%). The returns of the Reporting GHG portfolio show exposure to the orthogonalised returns of the Oil \& Gas industry, Industrials, Consumer Goods, Telecommunication and Utilities, i.e. returns of the portfolio have been corrected for their exposure to the performance of these industries. The Not Reporting GHG portfolio generates an annualised loss of $-2.62 \%$ ( $\mathrm{p}<0.01$, adjusted R-squared of over $99 \%$ ). The statistically significant exposure to the SMB factor for this portfolio is small but positive, suggesting that the Not Reporting GHG portfolio contains companies with a smaller market capitalization, which is intuitive as company size is known to determine environmental disclosure habits (Brammer et al. 2006; Patten 2002). The portfolio also shows a significant positive exposure on the HML factor, suggesting that it contains predominantly stocks with a high book to market ratio.

Table 2 around here 
An investor going long in companies reporting GHG emissions and short in companies not reporting GHG emissions generates an annualised alpha of $4.34 \%(\mathrm{p}<0.01)$. Although the GHG emissions data were obtained from publicly available sources, we concede, analogous to Ball (1994), that there are information costs, as well as hypothetical transaction costs involved in the gathering of information for this proxy and carrying out the investment strategy. As such, we also assess the significance of the abnormal risk-adjusted returns assuming a rather high annual total expense ratio of $1.5 \%$ for carrying out the investment strategy (cf. Renneboog et al. 2008; Geczy et al. 2005; Statman 2000). ${ }^{8}$ The alpha remains statistically significant with the expense ratio accounted for.

Our results suggest that the market is inefficient and that portfolios constructed from companies disclosing and those not disclosing quantitative GHG emissions show differences in risk-adjusted returns. Hypothesis H1 is consequently confirmed. The existence of disclosure of quantitative GHG emissions is relevant to asset prices.

Table 2 also presents the results of portfolios constructed from GHG emission disclosure completeness as operationalised in the Disclosure Completeness Index. Companies reporting complete GHG emissions, i.e. the 3 DCI Score portfolio, show a significant annualised return of $4.90 \%$ ( $p<0.05$, adjusted R-squared of $94 \%$ ). Furthermore, companies with incomplete GHG emissions reporting, i.e. the 0 DCI Score portfolio, show a significant annualised loss of $-8.15 \%$ ( $\mathrm{p}<0.01$, adjusted R-squared of 96\%). The 0 DCI Score portfolio shows significant positive exposure on the HML and UMD factors, suggesting that it contains

8 To that end, the annual total expense ratio is split into monthly expenses and deducted from the returns of the long-short portfolios and the regression is repeated. As a result, portfolio returns are reduced by $1.5 \%$ annually. In our study, results of all equal-weighted long-short portfolios remain statistically significant with the expense ratio accounted for, except for GHG efficiency, where the results of the long-short regression and robustness tests controlling for other non-financial disclosure (SG), as well as the completeness of GHG emissions reporting (comp. weighted), are no longer significant at conventional levels. 
predominantly value stocks which performed well historically. Interestingly, all other portfolios display very little exposure to the size, value and momentum effect, indicating that companies within the respective portfolios, on average, show little abnormality in terms of size, book to market ratio and historical performance. The fact that companies that only partially or anecdotally report on their emissions, i.e. show a DCI Score of 1 or 2 , do not generate statistically significant returns or losses, suggests that markets need clear signals and value information certainty.

A trading strategy that goes long in companies reporting completely (3 DCI Score portfolio) and short in companies reporting incompletely (0 DCI Score portfolio) generates an annualised alpha of $13.05 \%(\mathrm{p}<0.01)$. The differences in risk-adjusted returns suggest that the market is inefficient and values the quality of carbon disclosure as relevant. Hypothesis $\mathrm{H} 2$ is consequently confirmed. ${ }^{9}$ The completeness of disclosure of quantitative GHG emissions is relevant to asset prices.

Main regression results obtained with portfolios constructed from differing absolute levels of GHG emissions are also presented in Table 2. Both, the High GHG and the Medium GHG portfolio load significantly and negatively on the SMB factor, indicating that larger companies tend to have higher levels of GHG emissions, which is intuitive. The Low GHG portfolio generates an annualized alpha of $3.61 \%(\mathrm{p}<0.10$, adjusted R-squared of $98 \%)$. However, when hypothetical information and transaction costs are accounted for, the alpha of the Low GHG portfolio becomes statistically insignificant. In other words, when a total expense ratio of $1.50 \%$ is assumed, no statistically significant outperformance is found. There is also no outperformance of the long-short portfolio. Hypothesis H3 is consequently rejected,

The number of companies in the 3 Score and 0 Score portfolios is low in some of the years under analysis (see Table 1), yet still sufficiently high to ensure that portfolio results are not driven by the individual performance of a few companies. Given the use of equal-weighted returns, the possibility that portfolio results are driven by the individual performance of a few large companies in the portfolio is further reduced. 
as there are no substantial differences in risk-adjusted returns between portfolios constructed from companies with high, medium and low absolute levels of emissions.

Table 3 around here

Results of tests of our final proxy for carbon performance, GHG efficiency, are also presented in Table 2. The portfolio constructed from companies with a high GHG efficiency generates an annualised alpha of 3.04\% ( $\mathrm{p}<0.05$, adjusted R-squared of 97\%). The Medium GHG Efficiency portfolio shows an annualised return of $2.59 \%(\mathrm{p}<0.10$, adjusted R-squared of 98\%). The Low GHG Efficiency portfolio shows a negative performance but is statistically insignificant at conventional significance levels. A trading strategy going long in companies with a high GHG efficiency and short in companies with a low GHG efficiency generates an annualised alpha of $4.10 \%(\mathrm{p}<0.10)$. Results show that portfolios constructed from companies with high, medium and low GHG efficiency show differences in risk-adjusted returns. Hypothesis H4 is consequently confirmed. The market regards information on companies' GHG efficiency as relevant to asset prices.

It must be noted these main results are contingent upon the choices for our research design as discussed in the section on research methods. We believe, however, that choosing a local version of C4FM applied to a sample that excludes micro-caps and controls for industry effects (cf. Carhart 1997; Derwall et al. 2005; Fama et al. 2010; Fama et al. 2011, Geczy et al. 2005; Gregory et al., 2013; Hoepner et al. 2011) adheres to a current best available standard. To add further credence to our main results, we run a series of robustness tests, and we discuss these in the following section. 


\section{Further Analysis}

The analysis above shows that the relevance of information on carbon disclosure and performance in terms of GHG efficiency does not stem from factors known to determine abnormal risk-adjusted returns or the industry composition of the portfolios constructed. In this section, we perform further tests of robustness. Given the importance of the EU ETS to the financial impact of climate change on companies in Europe, as well as the fact that companies affiliated to the EU ETS are required to report scope $1 \mathrm{CO}_{2}$-emissions for parts of their activities (DEFRA 2011) and thus might have a spurious relation to portfolio construction, we control for companies' affiliation to the EU ETS in model (2). ${ }^{10}$ To that end, orthogonalised returns of an equal-weighted portfolio constructed from companies not affiliated with the EU ETS are deducted from orthogonalised returns of an equal-weighted portfolio constructed from companies affiliated to the EU ETS and the resulting factor (ETS) is added to the original C4FM model:

$R_{i t}-R_{f t}=\alpha_{i}+\beta_{i}\left(R_{m t}-R_{f t}\right)+s_{i} S M B_{t}+h_{i} H M L_{t}+p_{i} U M D_{t}+m_{i} E T S_{t}+\varepsilon_{i t}$

Where ETS $_{\mathrm{t}}$ is calculated by deducting orthogonalised returns of an equal-weighted portfolio constructed from companies not affiliated with the EU ETS from orthogonalised returns of an equal-weighted portfolio constructed from companies affiliated to the EU ETS. As shown in Table 3, results concerning our proxies relating to disclosure and the quality of disclosure remain statistically the same when controlling for the effect of affiliation to the EU ETS.

Table 3 around here

10 During the time of the study the EU ETS showed a clear industry focus. For example, for three out of the nine industries in our sample, less than $2 \%$ companies were affiliated with the EU ETS. We therefore do not control for industry affiliation in model (2). 
The results of performance-based portfolios are insignificant when the effect of affiliation to the EU ETS is controlled for (see Table 3). This finding suggests that the value relevance identified with regard to GHG efficiency - but not disclosure - is erased when companies' affiliation with the EU ETS is taken into account. In other words, the performance of portfolios constructed from GHG efficiency is correlated with affiliation to the EU ETS, thus suggesting that EU ETS legislation is related to GHG efficiency, which seems plausible.

While the EU ETS is the primary regulatory tool at the European level, fiscal ambitions to reduce carbon emissions differ across European countries. To control for these national differences, we use the level of implicit taxes on energy consumption (cf. Jeffrey et al. 2014) which is calculated by Eurostat as the energy tax revenues of a country in relation to its final energy consumption (Eurostat 2011a). Given that $79 \%$ of GHG emissions in the EU arise from energy (Eurostat 2011b), the implicit taxes on energy can indicate a country's level of ambition to reduce GHG emissions through national fiscal policies. Descriptive information on the country composition of our sample and the national implicit energy tax levels are shown in Appendix A. We derive country composition from the location of company headquarters. Accordingly, while this control captures national differences in fiscal policies, a potential shortcoming arises as companies in the sample have different levels of international activities and taxes are levied locally.

To control for countries' differing ambitions to reduce global warming through national fiscal policy, orthogonalised returns of equal-weighted portfolios constructed from companies originated in countries with an implicit energy tax rate below the median of the sample are deducted from orthogonalised returns of equal-weighted portfolios constructed from companies originated in countries with an implicit energy tax rate above the median of the sample and the resulting factor (Entax) is added to model (1). In doing so, we address the 
concern that differences in national environmental regulation impact our results. The statistical significance of results remains the same for the disclosure portfolios, while the portfolio constructed from GHG efficiency loses its statistical significance (see Table 3), suggesting that taxes on energy consumption are related to GHG efficiency, which seems plausible.

While the focus of our study is carbon disclosure and performance, disclosure on other non-financial issues might drive the results obtained. To control for this potential effect, we use an average of the social and governance disclosure score of Bloomberg (Bloomberg 2015).To that end, orthogonalised returns of equal-weighted portfolios constructed from companies with an average of Bloomberg social and governance score below the median of the sample are deducted from orthogonalised returns of equal-weighted portfolios constructed from companies with an average of Bloomberg social and governance score above the median of the sample and the resulting factor (SG) is added to model (1), while including companies where no score was available in a third portfolio (No Info SG). In doing so, we address the concern that the level of other non-financial disclosure drives our results. As can be seen from Table 3, results remain statistically the same for all portfolios.

In an additional test of robustness, the effect of the financial market crisis is controlled for. Following Hoepner and Zeume (2014), an additional control variable for financial market crisis is included in model (1), which corresponds to the accumulated drawdown of the stock market at month t. The control variable (Crisis) is coded zero in each month in which the market return $R_{m t}$ is above the risk free return $R_{f t}$. If the market return $R_{m t}$ is below the risk free return $R_{f t}$, the respective month is defined as a month of financial market crisis and the control variable corresponds to the absolute value of accumulated continuously compounded stock market excess return since the last month coded zero. The resulting factor is multiplied by -1 for ease of interpretation. Exposure on the Crisis factor is significant and positive for all 
portfolios except the existence of reporting, suggesting these portfolios outperform the market in months of financial market crisis, i.e. the crisis is not reducing the value relevance of the information assessed in this study.

To further test the robustness of our results, we construct and update all factors and portfolios in this study as of June of each year (June) in model (1). As can be seen from Table 3, our primary results hold and show higher risk-adjusted returns for all portfolios. We next control for the effect of outliers and construct the respective long-short portfolios using all companies except the smallest $5 \%$ and largest $5 \%$ of companies of the sample in terms of market capitalization (June, outlier). As reported in Table 3, results of equal-weighted portfolios remain statistically the same, except for portfolios constructed from levels of GHG efficiency, whose statistical significance is lowered to $p=0.12$. To control for the effect of alternative weighting procedures on our results, we repeat this analysis with value-weighted portfolio results regressed on value-weighted control factors in model (1) built in June (valueweighted, June, outlier). ${ }^{11}$ Results remain qualitatively the same for portfolios constructed from disclosure proxies (see Table 3). Interestingly, value-weighted results for portfolios constructed from absolute levels of GHG emissions and GHG efficiency show higher differences in risk-adjusted returns (see Table 3). For example, an investor going long in companies with high GHG efficiency and short in companies with low GHG efficiency generates an annualised alpha of $8.46 \%(\mathrm{p}<0.01)$.

Finally, as shown in Table 1, only a small percentage of our sample firms are reporting GHG emissions data in a complete manner. As such, it is possible that results for portfolios constructed from companies with low absolute levels of GHG emissions and high GHG

11 When portfolio returns are value-weighted they are winsorized using all companies except the smallest $5 \%$ and largest $5 \%$ of companies in terms of market capitalization. The largest $5 \%$ of over 340 companies in the sample present between $29 \%$ and $37 \%$ of the sample market capitalization in the months under investigation. We eliminated these outliers from the sample to ensure that these are not main drivers of our value-weighted results (cf. Edmans 2011; Gibson Brandon \& Wang 2013). 
efficiency are driven by incompletely reporting companies. To control for this potential bias, we weight our carbon performance based portfolios according to reporting completeness and repeat the analysis in model (1). More specifically, the score of a company on the DCI is divided by the sum of all scores of companies on the DCI in a respective portfolio at month t. The resulting disclosure completeness weight is multiplied with the returns of the respective stocks in the portfolio. The continuously compounded monthly return of an equal-weighted portfolio is then generated by computing the natural logarithm of the sum of the disclosureweighted returns of all stocks in the portfolio. As a result, the returns of a portfolio constructed from absolute levels of GHG emissions and weighted by disclosure completeness cannot be primarily driven by companies that report GHG emissions in an incomplete manner. Regression results are presented in Table 3. The statistical significance of results obtained with absolute levels of GHG emissions or GHG efficiency remains the same when controlling for the completeness of disclosure.

\section{Conclusion and Discussion}

Our analysis provides evidence that the existence and quality of corporate carbon disclosures, as well as the information on the level of GHG efficiency, is regarded as relevant to asset prices and not priced appropriately during the time of this study. We find only very limited support for information on absolute levels of GHG emissions being considered value relevant by financial markets over the same period. In summary, our findings thus suggest that disclosure proxies on corporate climate risk exposure are considered more relevant by financial markets than climate change performance expressed as absolute levels of GHG emissions. Possible explanations for this finding are that markets value information certainty, which in turn leads to among other things, better analyst forecasts (Dhaliwal et al. 2012) and lower estimation risk (see e.g. Barry et al. 1985), while absolute levels of GHG emissions are not considered an adequate proxy for climate change risk by market participants. Another 
explanation may be that market participants are not able to correctly evaluate the risk attached to absolute levels of GHG emissions or that disclosure serves to reduce investor uncertainty regardless of the level of absolute GHG performance.

Our results have three main implications relating to companies, investors and regulators. For companies, results show that information costs involved in corporate carbon disclosure and efficiency management do not present a burden on corporate financial resources, as they are relevant to asset pricing. Companies reporting (complete) GHG emissions in line with the GHG Protocol, GRI and the CDP generate significant risk-adjusted abnormal returns. At the same time, our results suggest that incompletely reporting companies were penalised by financial markets during the time of this study. We also find evidence, though less strong, that information on carbon performance is valued by the market. Results should thus motivate companies to engage in this type of high-quality non-financial disclosure and management.

For investors, results suggest they should no longer neglect information on carbon disclosure and performance when making investment decisions. In the state of market inefficiency evidenced in our study, investors could obtain abnormal risk-adjusted returns of up to $13.05 \%$ per year by exploiting the inappropriately priced positive effects of (complete) GHG emissions disclosure and good corporate climate change performance in terms of GHG efficiency. For example Schwert (2003) showed that inefficiencies disappear once they are published, i.e. research causes the market to become more efficient as a result of market participants acting on the arbitrage opportunities evidenced. Interestingly, when exploiting the arbitrage opportunities evidenced in this research, the interests of SRI and mainstream investors would appear to be aligned. The value-driven SRI investor (Derwall et al. 2011) would tend to invest in companies reporting (complete) GHG emissions and showing a comparatively good climate change performance for ethical reasons. The mainstream investor, out of purely financial motivation, would also invest in these companies in order to 
benefit from the inefficiency of the financial market to correctly price the positive effect of (complete) GHG emissions reporting and good climate change performance expressed as GHG efficiency. During this period of exploiting the market inefficiency identified, the interests of both types of investors would consequently be aligned, simultaneously resulting in a reduction of the exposure of their portfolios towards the information and estimation risk associated with companies that do not report (complete) GHG emissions and have low GHG efficiency.

As discussed, according to the EMH market participants will erase the abnormal riskadjusted returns identified by acting on arbitrage opportunities and, as a result, the financial market will at some point be efficient. In this scenario of market efficiency, investors will no longer be able to generate a risk-adjusted abnormal return by investing in companies that report (complete) GHG emissions and show a comparatively good climate change performance. However, in this scenario of an efficient market, the value-driven SRI investor does not act irrationally by investing in companies that, for example, show high GHG efficiency, as long as that the portfolio is reasonably diversified. Fama et al. (2007) believe that socially responsible investors trade in parts of their risk-adjusted return for knowledge that their investments do not violate their social or environmental conscience. If however, lower returns stem from lower systematic information and estimation risk, as it could be the case for companies reporting (complete) GHG emissions and showing high GHG efficiency, the socially responsible investor is not irrational and does not receive lower levels of riskadjusted returns (Liesen 2015).

Finally, our results suggest that in the evidenced inefficient state, the stock market does not sufficiently take into account the information and estimation risk related to carbon disclosure and performance when allocating ownership of capital stock. Inefficient allocation of capital comes at a cost not only to investors but to the whole economy, given that the 
valuation of financial assets has a strong effect on investments in real assets (Bodie et al. 2008; Barro 1990). If stock prices do not accurately reflect the intrinsic value of the firm, the beta coefficient calculated under consideration of these stock prices is incorrect.

Consequently, the cost of equity, which is often calculated based on historic betas, is also incorrect, and in turn the overall cost of capital of companies in our sample cannot be expected to be estimated correctly. When incorrect rates for the cost of capital of companies are used as hurdle rates for investment decisions by corporate decision makers, the capital in the economy is not allocated efficiently, as companies do not know their respective opportunity costs and therefore cannot correctly determine the profitability of capital investment decisions (Easley et al. 2004). As a result, all companies in the sample can be expected to pursue value-destroying projects and/or incorrectly reject value-enhancing projects, which would impede economic growth (Hayek 1941). In this context, it appears that strong regulation on mandatory and high-quality corporate climate change disclosure resulting in more standardised disclosure - would not only help increasing market efficiency (cf. Chung et al. 2012) but result in better investment decisions in the real economy, which should present a strong motivation for policy makers. 


\section{References}

Ball, R. (1994), 'The development, accomplishments and limitations of the theory of stock market efficiency', Managerial Finance, 20 (2,3), 3-3.

Banz, R. (1981), 'The relationship between return and market value of common stock', Journal of Financial Economics, 9, 3-18.

Barro, R. J. (1990), 'The Stock Market and Investment', The Review of Financial Studies, 3 (1), 115131.

Barry, C. B., and S. J. Brown (1985), 'Differential information and security market equilibrium', Journal of Financial Quantitative Analysis, 20 (4), 407-422.

Bloomberg (2015), 'Equities'. Available from http://www.bloomberg.com/professional/markets/equities/.

Bodie, Z., A. Kane, and A. J. Marcus (2008), 'The Efficient Market Hypothesis'. In Essentials of Investments. Boston: McGraw-Hill Irwin.

Brammer, S., and S. Pavelin (2006), 'Voluntary Environmental Disclosures by Large UK Companies', Journal of Business Finance \& Accounting, 33 (7-8), 1168-1188.

- - (2008), 'Factors Influencing the Quality of Corporate Environmental Disclosure', Business Strategy and the Environment, 17, 120-136.

Campbell, D., and R. Slack (2011), 'Environmental disclosure and environmental risk: Sceptical attitudes of UK sell-side bank analysts', The British Accounting Review, 43 (1), 54-64.

Carbon Disclosure Project (2006), 'Carbon Disclosure Project Report 2006 - Global FT500'. London: Carbon Disclosure Project.

- - (2008), 'Carbon Disclosure Project Report 2008 - Global 500'. London: Carbon Disclosure Project.

- - - (2011), 'Overview'. Available from https://www.cdproject.net/enUS/WhatWeDo/Pages/overview.aspx.

Carbon Market Data (2011), 'EU ETS Companies Database'. Available from http://www.carbonmarketdata.com/en/products/world-ets-database/presentation.

Carbon Trust (2006), 'Climate Change and Shareholder Value'. London: Carbon Trust.

Carhart, M. M. (1997), 'On Persistence in Mutual Fund Performance', The Journal of Finance, 52 (1), 57-82.

Chung, J., H. Kim, W. Kim, and Y. K. Yoo (2012), 'Effects of Disclosure Quality on Market Mispricing: Evidence from Derivative-Related Loss Announcements', Journal of Business Finance \& Accounting, 39 (7-8), 936-959.

Clarkson, P. M., Y. Li, and D. R. Gordon (2004), 'The Market Valuation of Environmental Capital Expenditures by Pulp and Paper Companies', The Accounting Review, 79 (2), 329-353.

Cormier, D., and M. Magnan (2007), 'The revisited contribution of environmental reporting to investors' valuation of a firm's earnings: An international perspective', Ecological Economics, $62(3-4), 613-626$

Cortez, M. C., F. Silva, and N. Areal (2012), 'Socially Responsible Investing In The Global Market: The Performance Of US And European Funds', International Journal of Finance \& Economics, 17 (3), 254-271.

Dawkins, C., and J. Fraas (2010), 'Coming Clean: The Impact of Environmental Performance and Visibility on Corporate Climate Change Disclosure', Journal of Business Ethics, 100 (2), 303322.

Deegan, C. (2007), 'Organizational legitimacy as a motive for sustainability reporting'. In Sustainability Accounting and Accountability, edited by J. Unerman, J. Bebbington and B. O'Dwyer. London: Routledge, 127-149.

Deegan, C., and M. Rankin (1997), 'The materiality of environmental information to users of annual reports', Accounting, Auditing \& Accountability Journal, 10 (4), 562-562.

DEFRA (2011), 'Measuring and reporting of greenhouse gas emissions by UK companies: a consultation on options'. London: Department for Environment, Food and Rural Affairs. 
Derwall, J., N. Guenster, R. Bauer, and K. Koedijk (2005), 'The Eco-Efficiency Premium Puzzle', Financial Analysts Journal, 61 (2), 51-63.

Derwall, J., K. Koedijk, and J. Ter Horst (2011), 'A tale of values-driven and profit-seeking social investors', Journal of Banking \&amp; Finance, 35 (8), 2137-2147.

Dess, G. G., R. D. Ireland, and M. A. Hitt (1990), 'Industry Effects and Strategic Management Research', Journal of Management, 16 (1), 7-27.

Dhaliwal, D. S., S. Radhakrishnan, A. Tsang, and Y. G. Yang (2012), 'Nonfinancial Disclosure and Analyst Forecast Accuracy: International Evidence on Corporate Social Responsibility Disclosure', The Accounting Review, 87 (3), 723-759.

Diageo (2008), 'Corporate Citizenship Report 2008'. London: Diageo plc.

Dimson, E., and M. Mussavian (1998), 'A brief history of market efficiency', European Financial Management, 4 (1), 91-103.

Dingwerth, K., and M. Eichinger (2010), 'Tamed transparency: how information disclosure under the Global Reporting Initiative fails to empower', Global Environmental Politics, 10 (3), 74-96.

Doda, B., C. Gennaioli, A. Gouldson, D. Grover, and R. Sullivan (2015), 'Are Corporate Carbon Management Practices Reducing Corporate Carbon Emissions?' Corporate Social Responsibility and Environmental Management, Early View (Article first published online: 28 MAR 2015), DOI: 10.1002/csr.1369.

Easley, D., and M. O'Hara (2004), 'Information and the Cost of Capital', The Journal of Finance, 59 (4), 1553-1583.

European Council (2006), 'Renewed EU Sustainable Development Strategy', edited by Council of the European Union. Brussels.

Eurostat (2011a), 'Driving forces behind EU-27 greenhouse gas emissions over the decade 19992008'. In Statistics in Focus - General and regional statistics Statistics in focus Environment and energy, edited by V. Bolla and V. Pendolovska. Brussels: European Union.

- - (2011b), 'Implicit tax rate on energy' . Available from http://epp.eurostat.ec.europa.eu/tgm/table.do?tab=table\&plugin=1\&language=en\&pcode=t sien040.

Fama, E. F. (1970), 'Efficient Capital Markets: A Review of Theory and Empirical Work', The Journal of Finance, 25 (2), 383-417.

- - (1998), 'Market efficiency, long-term returns, and behavioral finance', Journal of Financial Economics, 49, 283-306.

Fama, E. F., and K. French (1992), 'The cross-section of expected stock returns', Journal of Finance, 47, 427-465.

- - (1995), 'Size and Book-to-Market Factors in Earnings and Returns', The Journal of Finance, 50 (1), 131-155.

- - (2007), 'Disagreement, tastes, and asset prices', Journal of Financial Economics, 83 (3), 667689.

- - (2010), 'Luck versus Skill in the cross-section of mutual fund returns', Journal of Finance, 65 (5), 1915-1947.

- - (2011), 'Size, Value and Momentum in International Stock Returns', Tuck School of Business Working Paper No. 2011-85, Chicago Booth Research Paper No. 11-10. Available at SSRN: http://ssrn.com/abstract= 1720139 .

Foerster, S. R., and S. G. Sapp (2005), 'Valuation of financial versus non-financial firms: a global perspective', Journal of International Financial Markets, Institutions and Money, 15 (1), 1-20.

Francis, J., R. LaFond, P. Olsson, and K. Schipper (2005), 'The market pricing of accruals quality', Journal of Accounting and Economics, 39 (2), 295-327.

Freeman, R. E. (1994), 'The politics of stakeholder theory', Business Ethics, 4 (4), 409-421.

FTSE Group (2010), 'Industry Classification Benchmark (ICB)'. Available from www.icbenchmark.com

FTSE Group (2012), 'FTSE CDP Carbon Strategy Index Series'. Available from http://www.ftse.com/Indices/FTSE_CDP_Carbon_Strategy_Index_Series/Downloads/FTSE_C DP_Carbon_Strategy_Methodology_Overview.pdf. 
Geczy, C. C., R. F. Stambaugh, and D. Levin (2005), 'Investing in Socially Responsible Mutual Funds'. SSRN Working Paper. Available from http://ssrn.com/paper=416380.

Gibson Brandon, R., and S. Wang (2013), 'Liquidity Risk, Return Predictability, and Hedge Funds' Performance: An Empirical Study', Journal of Financial and Quantitative Analysis, 48 (01), 219-244.

Global Reporting Initiative (2000-2006), 'G3 Guidelines - Sustainability Reporting Guidelines'. Amsterdam.

- - (2011), 'Sustainability Reporting guidelines - Version 3.1'. Amsterdam.

Gregory, A., Tharyan, R. and A. Christidis (2013), 'Constructing and Testing Alternative Versions of the Fama-French and Carhart Models in the UK', Journal of Business Finance \& Accounting, 40 (1-2), 172-214.

Grossmann, S. J., and J. E. Stiglitz (1980), 'On the Impossibility of Informationally Efficient Markets', The American Economic Review, 70 (3), 393-408.

Hassel, L., and H. Nilsson (2006), 'An empirical study of the actual use of environmental information by financial analysts'. Proceedings of Nordic Academy of Management 1st Winter Conference. Umeå (16-18 March 2006).

Hayek, F. A. (1941), 'The Pure Theory of Capital'. Chicago: University of Chicago Press.

Hoepner, A. G., H. G. Rammal, and M. Rezec (2011), 'Islamic Mutual Funds Financial Performance and International Investment Style: Evidence from 20 Countries', European Journal of Finance, Forthcoming, 17 (9-10), 829-850.

Hoepner, A. G., and S. Zeume (2014), 'Fiduciary Duty and 'Sin Stocks': is vice really nice?'. In Handbook of institutional investment and fiduciary duty, edited by J. P. Hawley, A. G. F. Hoepner, K. L. Johnson, J. Sandberg and E. J. Waitzer. Cambridge: Cambridge University Press, 181-206.

Hoepner, A., Oikonomou, I., Scholtens, B. and M. Schröder (2016), 'The Effects of Corporate and Country Sustainability Characteristics on The Cost of Debt: An International Investigation', Journal of Business Finance \& Accounting, 43 (1-2), 158-190.

IIGCC (2010), 'The Institutional Investors Group on Climate Change'. IIGCC 2010. Available from www.iigcc.org.

Innovest (2007), 'Carbon Beta and Equity Performance: An Empirical Analysis'. New York: Innovest Strategic Value Advisors.

Investor Network on Climate Risk (2010), 'About INCR '. Available from http://www.ceres.org/incr/about.

IPCC (2007), 'Climate Change 2007: The Physical Science Basis - Summary for Policymakers'. Geneva: Intergovernmental Panel on Climate Change.

Jeffrey, C., and J. D. Perkins (2014), 'The Relationship between Energy Taxation and Business Environmental Protection Expenditures in the European Union', The International Journal of Accounting, 49 (4), 403-425.

Jegadeesh, N., and S. Titman (1993), 'Returns to Buying Winners and Selling Losers: Implications for Stock Market Efficiency', Journal of Finance, 48 (1), 65-91.

Kanter, J. (2009), 'Council in France Blocks a Carbon Tax as Weak on Polluters'. The New York Times, December 30th.

Kim, D., and Y. Qi (2010), 'Accruals Quality, Stock Returns, and Macroeconomic Conditions', Accounting Review, 85 (3), 937-978.

Kolk, A., D. Levy, and J. Pinkse (2008), 'Corporate Responses in an Emerging Climate Regime: The Institutionalization and Commensuration of Carbon Disclosure', European Accounting Review, 17 (4), 719-745.

Lee, C. M. C. (2001), 'Market efficiency and accounting research: a discussion of 'capital market research in accounting' by S.P. Kothari', Journal of Accounting and Economics, 31, 233-253.

Leuz, C., and R. Verrecchia (2005), 'Firms' capital allocation choices, information quality, and the cost of capital'. Working Paper. Philadelphia: University of Pennsylvania. 
Liesen, A. (2015), 'Climate Change and Financial Market Efficiency', Business \& Society, 54 (4), 511539.

Liesen, A., A. G. Hoepner, D. M. Patten, and F. Figge (2015), 'Does stakeholder pressure influence corporate GHG emissions reporting? Empirical evidence from Europe', Accounting, Auditing \& Accountability Journal, 28 (7), 1047-1074.

Lintner, J. (1965), 'The valuation of risk assets and the selection of risky investments in stock portfolios and capital budgets', Review of Economics and Statistics, 17, 13-37.

Luo, X., and C. B. Bhattacharya (2009), 'The Debate over Doing Good: Corporate Social Performance, Strategic Marketing Levers, and Firm-Idiosyncratic Risk', Journal of Marketing, 73 (6), 198213.

Mahapatra, S. (1984), 'Investor Reaction to Corporate Social Accounting', Journal of Business Finance \& Accounting, $11(1), 29-40$.

Mossin, J. (1966), 'Equilibrium in a capital asset market', Econometrica, 34 (October), 768-783.

Pattberg, P. (2012), 'How climate change became a business risk: analyzing nonstate agency in global climate politics', Environment and Planning C: Government and Policy, 30 (4), 613-626.

Patten, D. M. (2002), 'The relation between environmental performance and environmental disclosure: a research note', Accounting, Organizations and Society, 27 (8), 763-773.

Prado-Lorenzo, J.-M., L. Rodríguez-Domínguez, I. Gallego-Álvarez, and I.-M. García-Sánchez (2009), 'Factors influencing the disclosure of greenhouse gas emissions in companies world-wide', Management Decision, 47 (7), 1133-1157.

Reed Elsevier (2005), 'Making an Impact - Corporate Responsibility Report 2005'. London: Reed Elsevier Ltd.

Renneboog, L., J. Ter Horst, and C. Zhang (2008), 'Socially responsible investments: Institutional aspects, performance, and investor behavior', Journal of Banking and Finance, 32 (9), 17231742.

Renshaw, E. F. (1984), 'Stock Market Panics: A Test of the Efficient Market Hypothesis', Financial Analysts Journal, 40 (3), 48-51.

Riedl, E. J., and G. Serafeim (2009) 'Information Risk and Fair Value: An Examination of Equity Betas and Bid-Ask Spreads'. Working paper 10-008. Boston: Harvard Business School.

Salama, A., K. Anderson, and J. S. Toms (2011), 'Does community and environmental responsibility affect firm risk? Evidence from UK panel data 1994-2006', Business Ethics: A European Review, 20 (2), 192-204.

Schwert, G. W. (2003), 'Anomalies and market efficiency'. In Handbook of the Economics of Finance, edited by Constantinides G.M., M. Harris and R. M. Stulz. Amsterdam: Elsevier, 939-974.

Sharpe, W. (1964), 'Capital Asset Prices: A Theory of Market Equilibrium under Conditions of Risk', Journal of Finance, 19 (3), 425-442.

Shleifer, A., and R. W. Vishny (1997), 'A survey of corporate governance', Journal of Finance, 52 (2), 737-783.

Statman, M. (2000), 'Socially Responsible Mutual Funds', Financial Analysts Journal, 56 (3), 30-39.

Stern, N. (2006), 'Stern Review: The Economics of Climate Change'. Cambridge: Cambridge University Press.

Sullivan, R. (2009), 'The management of greenhouse gas emissions in large European companies', Corporate Social Responsibility and Environmental Management, 16 (6), 301-309.

The Carbon Principles Banks (2008), 'Statement of Intent'. Available from http://carbonprinciples.org/intent.php.

The Climate Group (2012), 'The Climate Principles'. Available from http://www.theclimategroup.org/programs/the-climate-principles/.

The Goldman Sachs Group (2009), 'Change is coming: A framework for climate change - a defining issue of the 21st century'. Available from http://www.goldmansachs.com/our-thinking/gssustain/gs-sustain/climate-change-research-pdf.pdf.

Triami Media (2011), 'Euribor interest rates 2009'. Available from http://de.euribor-rates.eu/euribor2009. asp? $\mathrm{i} 1=6 \& \mathrm{i} 2=1$. 
von Arx, U., and A. Ziegler (2014), 'The effect of corporate social responsibility on stock performance: new evidence for the USA and Europe', Quantitative Finance, 14 (6), 977-991.

WBCSD (2004), 'The Greenhouse Gas Protocol - A Corporate Accounting and Reporting Standard'. Conches-Geneva and Washington: World Resources Institute, World Business Council for Sustainable Development.

Worthington, A. C., and H. Higgs (2004), 'Random walks and market efficiency in European equity markets', Global Journal of Finance and Economics, 1 (1), 59-78.

Ziegler, A., T. Busch, and V. H. Hoffmann (2011), 'Disclosed corporate responses to climate change and stock performance: An international empirical analysis', Energy Economics, 33 (6), 12831294. 